\title{
UNUSUAL PENETRATING INJURY OF THE ORBIT*
}

\author{
BY
}

\author{
M. LALLA† AND S. PILLAI \\ Bridgend General Hospital, Glamorgan
}

\section{Case Report}

A young woman aged 19 years suffered a penetrating injury to the right orbit when she fell downstairs and the umbrella that she was holding was driven through the roof of the right orbit into the frontal lobe, extending up to the parietal region.

When seen in Bridgend General Hospital she was comatose, with a flaccid left hemiparesis, and four inches of umbrella handle was protruding from the orbit (Figure). When the handle was removed the intra-cranial portion was found to measure six inches.

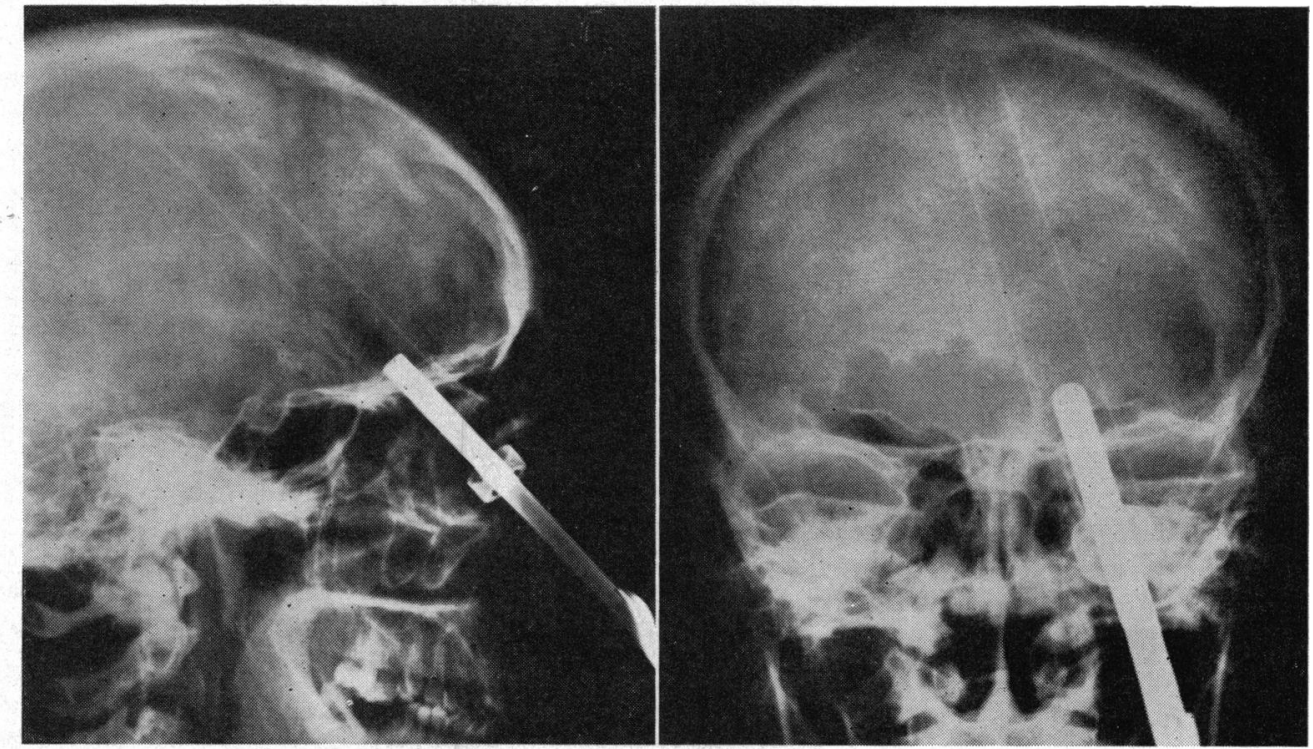

FIGURE.-Lateral and antero-posterior views of the skull. 6 inches of the intra-cranial section of the handle was covered by a plastic cover which is seen as a negative track on the radiographs.

Repair of the orbital wound with a drainage tube was carried out, and to our surprise there was very little bleeding and no leakage of cerebrospinal fluid.

The next day the patient was conscious and able to give a full account of the accident. She still had the left flaccid hemiparesis, and was transferred to the Neurosurgical Unit at Cardiff where, after a few days, surgical debridement was carried out.

Result.-The patient was alert, normally orientated, continent, and not euphoric. There has been a remarkable recovery of the hemiparesis, with only residual weakness in the left leg, and no sensory loss. She can walk well with a support to stabilize her ankle and a tripod.

The right eye shows slight residual ptosis, with full ocular movements. The visual acuity is only $6 / 24$, but this is due to a right convergent squint which was being treated at Neath before the accident. The visual acuity of the left eye is $6 / 6$.

\section{Summary}

A remarkable recovery followed very extensive intra-cranial injury, with no ocular damage.

Our thanks are due to Dr. P. K. D. Edmunds, consultant radiologist, for the $x$-ray plates.

* Received for publication March 23, 1964

† Present address: Royal Gwent Hospital, Newport, Mon. 